\title{
Design and Experimental Analysis of Multiband Compound Reconfigurable 5G Antenna for Sub-6 GHz Wireless Applications
}

\author{
Ikhlas Ahmad, ${ }^{1}$ Haris Dildar, ${ }^{1}$ Wasi Ur Rehman Khan, ${ }^{1}$ Syed Amir Ali Shah, ${ }^{1}$ Shakir Ullah, \\ Sadiq Ullah, ${ }^{1}$ Syed Muhammad Umar, ${ }^{1}$ Mahmoud A. Albreem $\left({ }^{1},{ }^{2}\right.$ \\ Mohammed H. Alsharif $\left(\mathbb{D},{ }^{3}\right.$ and Kasturi Vasudevan $\mathbb{1}^{4}$ \\ ${ }^{1}$ Department of Telecommunication Engineering, University of Engineering \& Technology, 23200 Mardan, Pakistan \\ ${ }^{2}$ Department of Electronics and Communications Engineering, A'Sharqiyah University, Ibra 400, Oman \\ ${ }^{3}$ Department of Electrical Engineering, College of Electronics and Information Engineering, Sejong University, 209 Neungdong-ro, \\ Gwangjin-gu, Seoul 05006, Republic of Korea \\ ${ }^{4}$ Department of Electrical Engineering, Indian Institute of Technology, Kanpur, India
}

Correspondence should be addressed to Mahmoud A. Albreem; mahmoud.albreem@asu.edu.om

Received 17 January 2021; Revised 19 February 2021; Accepted 5 April 2021; Published 20 April 2021

Academic Editor: Xianfu Chen

Copyright ( 2021 Ikhlas Ahmad et al. This is an open access article distributed under the Creative Commons Attribution License, which permits unrestricted use, distribution, and reproduction in any medium, provided the original work is properly cited.

In this paper, a printed low-profile antenna with frequency and pattern reconfigurable functionality is designed in three modes. Each mode operates at different frequency bands and has several options available for pattern reconfiguration in these bands. The proposed antenna consists of eight pin-diode switches (S1 to S8). The switches S1 and S2, installed in the radiating patch, are used for frequency reconfigurability to control the operating bands of the antenna. The rest of the six switches (S3, S4, S5, $\mathrm{S6}, \mathrm{S7}$, and S8), loaded in the stubs on the rear side of the antenna, are used for pattern reconfiguration to control the main lobe beam steering. When all switches are off, the proposed antenna operates in a wideband mode, covering the $3.82-9.32 \mathrm{GHz}$ frequency range. When $\mathrm{S} 1$ is on, the antenna resonates in the $3.5 \mathrm{GHz}(3.09-4.17 \mathrm{GHz})$ band. When both $\mathrm{S} 1$ and $\mathrm{S} 2$ are on, the resonant band of the antenna is shifted to $2.5 \mathrm{GHz}$ band $(2.40-2.81 \mathrm{GHz})$. A very good impedance matching with a return loss of less than $-10 \mathrm{~dB}$ is attained in these bands. The beam steering is done at each operating frequency by controlling the on and off states of the six pin-diode switches (S3, S4, S5, S6, S7, and S8). Depending on the state of the switches, the antenna can direct the beam in seven distinct directions at $4.2 \mathrm{GHz}, 4.5 \mathrm{GHz}$, and $5 \mathrm{GHz}$. The main beam of the radiation pattern is steered in five different directions at $5.5 \mathrm{GHz}, 3.5 \mathrm{GHz}$, and $2.6 \mathrm{GHz}$ operating bands for the given state of the mentioned switches. The proposed antenna supports several sub- $6 \mathrm{GHz} 5 \mathrm{G}$ bands $(2.6 \mathrm{GHz}, 3.5 \mathrm{GHz}, 4.2 \mathrm{GHz}, 4.5 \mathrm{GHz}$, and $5 \mathrm{GHz})$ and can be used in handheld $5 \mathrm{G}$ devices.

\section{Introduction}

Nowadays, with the fastest development of modern wireless communication technologies operating over a wide range of frequencies, the new $5 \mathrm{G}$ radio access networks are expected to simultaneously support the number of connections. To enable 5G, FCC has divided the main spectrum into low bandwidth (up to $1 \mathrm{GHz}$ ), medium band (below $6 \mathrm{GHz}$ ), and high bandwidth (mm wave) $[1,2]$. The millimeter wave offers data rates over $2 \mathrm{Gbps}$ and huge capacity, while low bandwidth offers good $5 \mathrm{G}$ coverage and medium band offers a combina- tion of both. It is clearly desirable to use the $5 \mathrm{G}$ millimeter wave spectrum to achieve the goal of superfast data rates. However, there are some critical challenges that need to be addressed before millimeter wave mobile communication can be implemented. In addition, the millimeter waves are prone to atmospheric attenuation and cannot propagate longer distances. On the other hand, the sub- $6 \mathrm{GHz}$ waves can propagate longer distances as compared to the millimeter waves and hence an affordable choice for long range, high data rate communication systems. Before the completion of millimeter wave technology for $5 \mathrm{G}$ communication, technology 


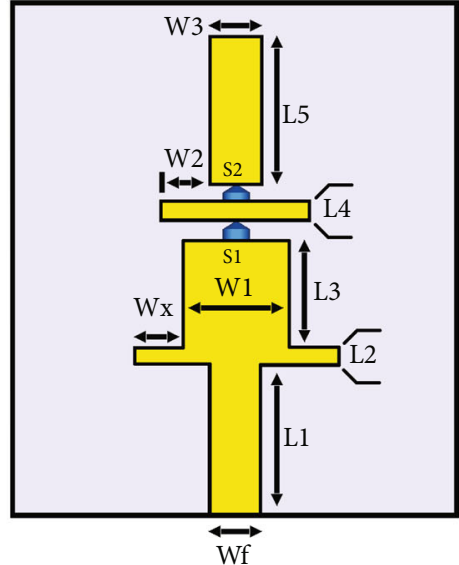

Front view

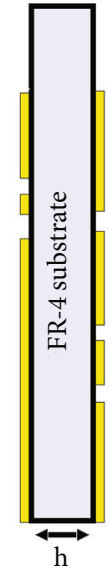

Side view

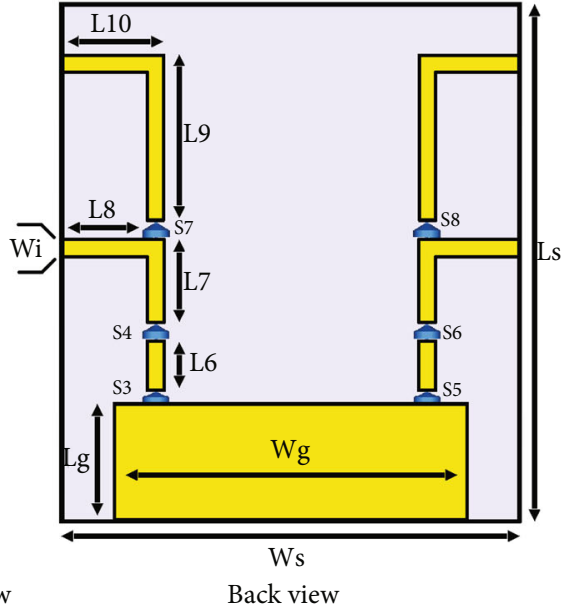

Figure 1: Geometric views of the proposed antenna.

below $6 \mathrm{GHz}$ would soon switch to $5 \mathrm{G}$. Since $5 \mathrm{G}$ communication below $6 \mathrm{GHz}$ can send high data rates over long distances, it is suitable for use in both urban and rural areas. With advancement in wireless communication technology, the reconfigurable antennas take much attention due to switching their characteristics according to user requirements [3]. Frequency reconfigurable antennas provide frequency tuning over desired frequency bands and efficient utilization of spectrum [4] while pattern reconfigurable antennas focus the signals towards intended direction, enhance the gain, save the energy [5], and decrease the effect of in-band interference and improve the channel capacity $[6,7]$. In the literature, most of the work is reported on antenna's single characteristic reconfiguration. In [8], a frequency reconfigurable hookshaped antenna for multiple applications is presented. A novel shaped hexaband frequency reconfigurable antenna for $\mathrm{Wi}$ Fi, WLAN, Wi MAX, and UMTS applications is presented in [9]. A low-profile frequency reconfigurable antenna for ISM, WLAN, Wi-Fi, and Airport Surveillance Radar band applications is reported in [10]. In [11,12], frequency reconfigurable antenna for WLAN and sub- $6 \mathrm{GHz} 5 \mathrm{G}$ applications is presented. A base station dual-band dual-polarized filtering antenna with high selectivity is proposed for $5 \mathrm{G}$ sub- $6 \mathrm{GHz}$ application which is discussed in [13], whereas frequency reconfigurable antenna operating in four bands is presented covered in [14]. A pattern reconfigurable Yagi-Uda antenna having directional and omnidirectional radiation pattern characteristics is proposed in [15]. In [16], a pattern reconfigurable antenna with partially reflective surface (PRS) for gain enhancement is presented; the reported antenna can steer the beam along $+78^{\circ}, 0^{\circ}$, and $-78^{\circ}$ at $1.815 \mathrm{GHz}$. In [17], a $2.45 \mathrm{GHz}$ pattern reconfigurable antenna for wireless sensor network (WSN) applications is introduced, which can switch the beam along $0^{\circ}$ and $\pm 80^{\circ}$. A compact single-element pattern reconfigurable antenna is reported in [18], with a beam scanning range of $-34^{\circ}$ to $+32^{\circ}$ at $2.29 \mathrm{GHz}$. Some other pattern reconfigurable antennas are presented in [19-21], which use different methods of pattern reconfigurability, i.e., complementary split ring resonators (CSRR) on the ground, switches with dielectric resonator, and microelectromechanical switches (MEMS) with coupling cells, respectively.

TABLE 1: Design parameters of the proposed antenna.

\begin{tabular}{lccc}
\hline Parameters & Values $(\mathrm{mm})$ & Parameters & Values $(\mathrm{mm})$ \\
\hline Ws & 27 & L4 & 1 \\
Ls & 31 & L5 & 9 \\
Wg & 21 & L6 & 3 \\
Lg & 7 & L7 & 5 \\
Wf & 3 & L8 & 6 \\
L1 & 9.2 & L9 & 10 \\
L2 & 1 & L10 & 6 \\
L3 & 6.5 & W1 & 6.5 \\
Wi & 1 & W2 & 2.5 \\
Wx & 3 & W3 & 3 \\
H & 1.6 & & \\
\hline
\end{tabular}

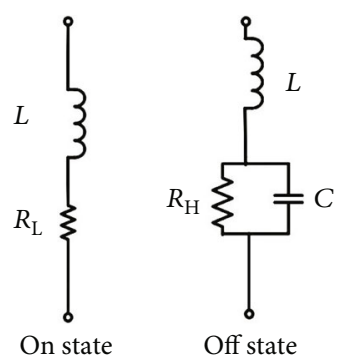

Figure 2: Pin diode model and its equivalent circuits.

The rapid advancement in communication technology demands multifunctional reconfigurations in a single antenna. In literature, some antennas have been reported having both frequency and pattern reconfigurability features. A frequency and pattern reconfigurable slot antenna is presented in [22], which has eleven pin diodes for reconfigurability to switch the frequency to three unique bands $(1.82 \mathrm{GHz}, 1.93 \mathrm{GHz}$, and $2.10 \mathrm{GHz})$ and can direct the beam in $+15^{\circ}, 0^{\circ}$, and $-15^{\circ}$. In [23], a two-element array antenna with frequency and pattern reconfigurable options is reported; the antenna employs two varactor diodes for frequency tuning in 


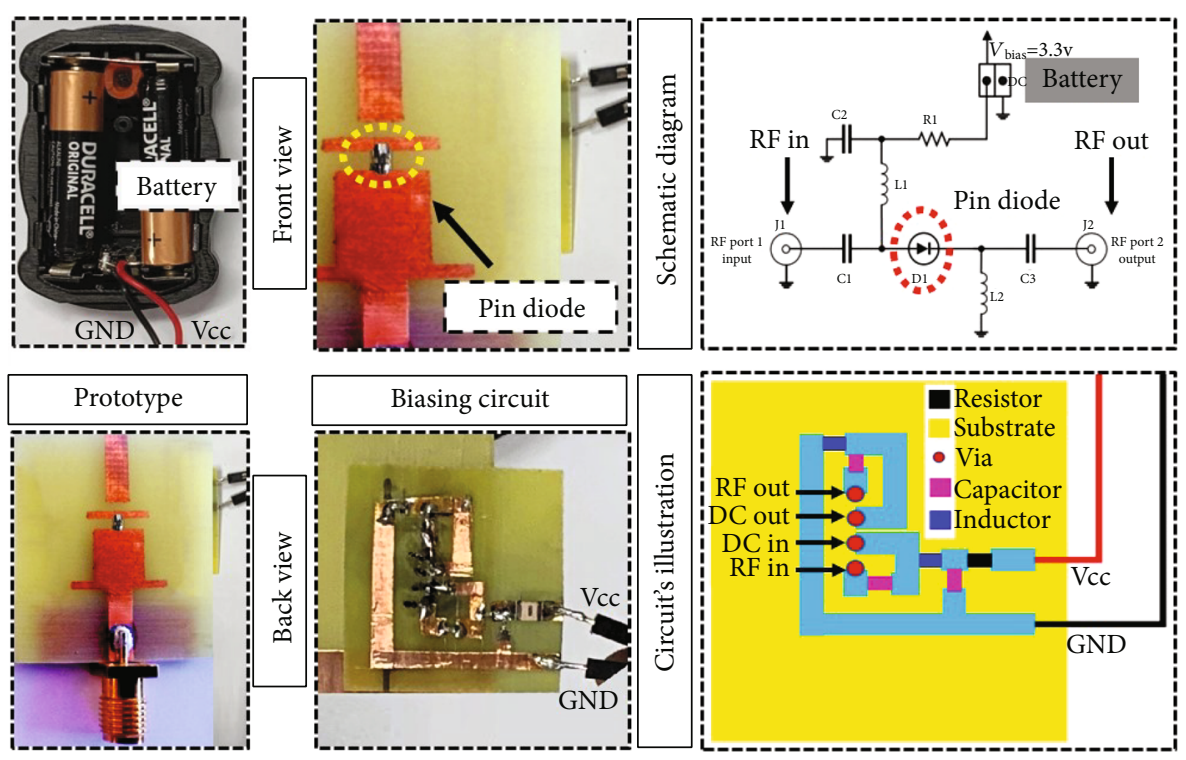

Figure 3: Fabricated prototype and biasing configuration for one of the eight pin-diode switches.

TABLE 2: Switching modes and related special cases.

\begin{tabular}{|c|c|}
\hline Modes & Special cases \\
\hline Mode $1(\mathrm{~S} 1=$ off, $\mathrm{S} 2=$ off $)$ & $\begin{array}{c}\mathrm{C} 1(\mathrm{~S} 3-\mathrm{S} 8=\mathrm{off}), \mathrm{C} 2(\mathrm{~S} 6=\text { on }), \mathrm{C} 3(\mathrm{~S} 4=\text { on }), \mathrm{C} 4(\mathrm{~S} 4-\mathrm{S} 6=\text { on }), \mathrm{C} 5(\mathrm{~S} 3, \mathrm{~S} 4, \& \mathrm{~S} 6=\mathrm{on}) \\
\mathrm{C} 6(\mathrm{~S} 5 \& \mathrm{~S} 6=\mathrm{on}), \mathrm{C} 7(\mathrm{~S} 3 \& \mathrm{~S} 4=\text { on })\end{array}$ \\
\hline Mode $2(\mathrm{~S} 1=$ on, $\mathrm{S} 2=$ off $)$ & $\mathrm{C} 1(\mathrm{~S} 3-\mathrm{S} 8=$ off $), \mathrm{C} 2(\mathrm{~S} 5=$ on $), \mathrm{C} 3(\mathrm{~S} 3=$ on $), \mathrm{C} 4(\mathrm{~S} 3, \mathrm{~S} 5, \& \mathrm{~S} 6=$ on $), \mathrm{C} 5(\mathrm{~S} 3-\mathrm{S} 5=$ on $)$ \\
\hline Mode $3(\mathrm{~S} 1=$ on, $\mathrm{S} 2=$ on $)$ & $\mathrm{C} 1(\mathrm{~S} 3-\mathrm{S} 8=\mathrm{off}), \mathrm{C} 2(\mathrm{~S} 6, \mathrm{~S} 8=\mathrm{on}), \mathrm{C} 3(\mathrm{~S} 4, \mathrm{~S} 7=$ on $), \mathrm{C} 4(\mathrm{~S} 5, \mathrm{~S} 6, \& \mathrm{~S} 8=$ on $), \mathrm{C} 5(\mathrm{~S} 3, \mathrm{~S} 4, \& \mathrm{~S} 7=\mathrm{on})$ \\
\hline
\end{tabular}

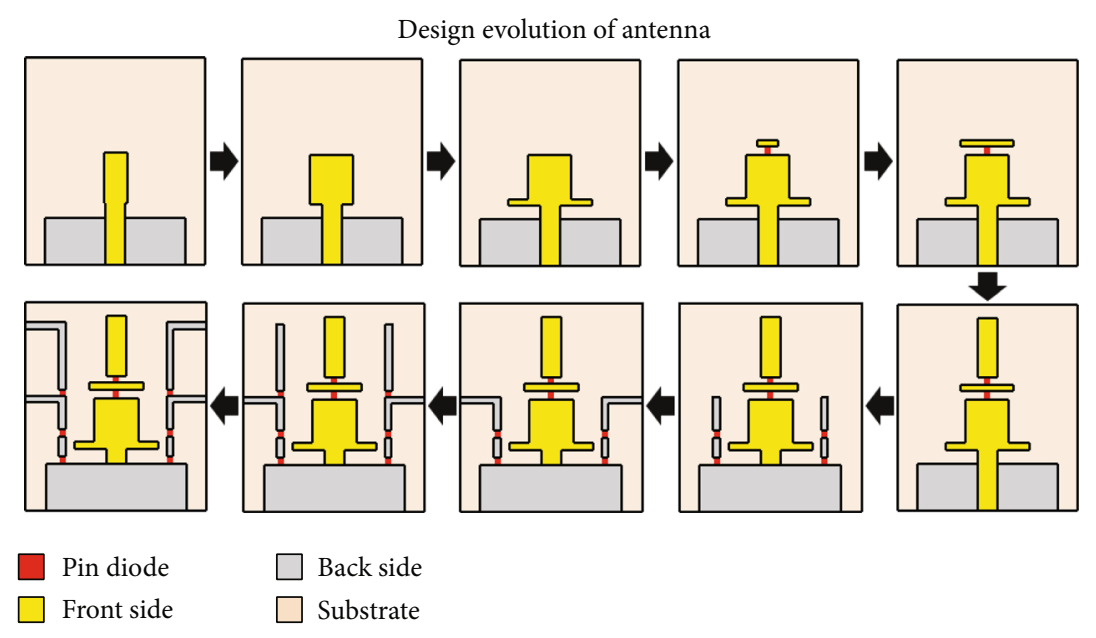

FIGURE 4: The evolution map highlighting various design stages of the proposed antenna.

a range of $2.15 \mathrm{GHz}$ to $2.38 \mathrm{GHz}$ and beam scanning in a range of $-23^{\circ}$ to $+23^{\circ}$. An aperture-coupled frequency and pattern reconfigurable antenna is introduced in [24], which hosts twelve pin diodes for switching; there are only two frequency bands of $2.6 \mathrm{GHz}$ and $3.5 \mathrm{GHz}$. The radiation pattern is steered along $+32^{\circ},+3^{\circ}$, or $-1^{\circ}$ at $2.6 \mathrm{GHz}$ or at $+28^{\circ},+23^{\circ}$, or $-24^{\circ}$ at $3.5 \mathrm{GHz}$. The antenna presented in [25] can reconfigure its frequency to $2.4 \mathrm{GHz}$ and $5.8 \mathrm{GHz}$ and can reconfigure the pattern by configuration of pin diodes loaded within the electromagnetic bandgap (EGB) unit cells. In [26], a frequency and radiation pattern reconfigurable antenna is designed; the antenna uses a pair of pin diodes, fixed in the slits of patch for frequency and pattern reconfiguration. The antenna has operating frequencies of $4.5 \mathrm{GHz}$ and 4.8 GHz/5.2 GHz and $5.8 \mathrm{GHz}$ and can steer the pattern along $-30^{\circ}, 0^{\circ}$, and $+30^{\circ}$. A flexible frequency and pattern reconfigurable antenna, hosting eight pin-diode switches, is presented in [27]. Frequency reconfiguration in $1.9 \mathrm{GHz}$ and $2.4 \mathrm{GHz}$ band 
beam steering in two directions can be achieved in each band for a given combination of switching state. In [28], a frequency and pattern reconfigurable wideband slot antenna is introduced, which encompasses four pin diodes for reconfigurability. Two pin diodes are used for frequency reconfigurability and two for pattern reconfigurability. The antenna covers two bands $3.4-3.8 \mathrm{GHz}$ and $3.7-4.2 \mathrm{GHz}$ and provide $20^{\circ}$ and $25^{\circ}$ beam steering. However, as the $5 \mathrm{G}$ services and multiple autonomous applications [29] in modern wireless communication, the multiple-input multiple-output (MIMO) antenna has improved and gives us substantial progress in link capacity as well as data throughput within the existing transmission and power $[30,31]$.

A compact size $\left(31 \times 27 \times 1.6 \mathrm{~mm}^{3}\right)$ multiband compound reconfigurable antenna having both frequency reconfigurability and pattern reconfigurability is presented in this paper. The compound reconfigurability is achieved using eight pindiode switches; two switches ( 1 1 and S2) are for frequency reconfigurability, and the other six switches (S3-S8) control the beam steering. The antenna operates at three modes. Each mode selects different frequencies and has several cases for beam steering over the operating frequencies. The antenna covers a wideband of $3.09-4.17 \mathrm{GHz}$ in mode 1 . In mode 2 and mode 3 , the antenna operates at $3.5 \mathrm{GHz}$ and $2.6 \mathrm{GHz}$ bands, respectively. The simulated results show that the designed antenna can direct the beam in seven different directions for $4.2 \mathrm{GHz}, 4.5 \mathrm{GHz}$, and $5 \mathrm{GHz}$ and in five distinct directions for $5.5 \mathrm{GHz}, 3.5 \mathrm{GHz}$, and $2.6 \mathrm{GHz}$ bands with acceptable peak gain. The proposed antenna supports several sub- $6 \mathrm{GHz}$ $5 \mathrm{G}$ bands $(2.6 \mathrm{GHz}, 3.5 \mathrm{GHz}, 4.2 \mathrm{GHz}, 4.5 \mathrm{GHz}$, and $5 \mathrm{GHz})$. The antenna can be used in $5 \mathrm{G}$ mobile applications.

The comparison of the proposed antenna work with other reported works shows that the proposed hybrid reconfigurable antenna provides a better solution for modern communication systems, where both frequency reconfigurability and pattern reconfigurability are required in a single antenna.

This paper is organized as follows: Section 2 explains the design methodology and geometry of the proposed antenna. Section 3 involves discussion about the simulation and measured results' evaluation. Section 4 concludes the proposed research work.

\section{Antenna's Design Methodology and Geometry}

The geometry of the proposed hybrid antenna is illustrated in Figure 1 . The radiator and ground of the proposed structure are printed on FR-4 substrate of thickness $1.6 \mathrm{~mm}$ with relative permittivity, $\varepsilon_{r}$, of 4.3 and loss tangent, $\delta$, of 0.025 . The proposed antenna has an overall size of $31 \times 27 \times 1.6 \mathrm{~mm}^{3}$. For feeding, a $3 \mathrm{~mm}$ wide microstrip line of $50 \Omega$ impedance is used. All design dimensions of the proposed structure are presented in Table 1.

The effective resonant lengths for intended operating frequencies are calculated using Equations (1) and (2).

$$
L_{f}=\frac{c}{4 f \sqrt{\mathscr{E}_{\mathrm{eff}}}},
$$
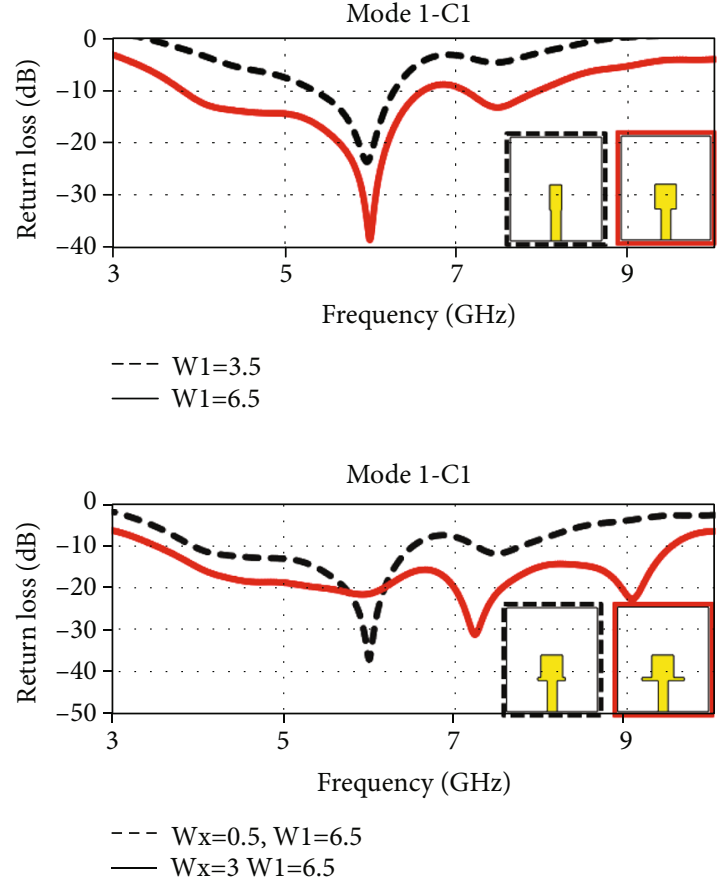

FIGURE 5: Design evolution of mode 1-C1 of the proposed antenna.

$$
\mathscr{E}_{\text {eff }}=\frac{\mathscr{E}_{r}+1}{2}+\frac{\mathscr{E}_{r}-1}{2}\left(1+12\left(\frac{w}{h}\right)\right)^{-0.5},
$$

where " $c$ " is the speed of light in vacuum, " $\mathscr{E}_{\text {eff }}$ " is effective dielectric constant, " $h$ " is the thickness, and " $w$ " is width of substrate.

In the radiating structure, a main radiator is designed along with two parasitic patches. The main radiator and parasitic patches are connected via pin diodes (SMP1345079LF). The on and off states of pin diodes result in opening and shortening of the connections between the patches and hence altering the resonant length of the antenna to reconfigure the operating frequency.

For pattern reconfiguration, six pin-diode switches are installed in the inverted L-shaped stubs of different sizes on the rear side of the antenna. The state of these six switches controls the distribution and density of surface currents across the antenna structure, resulting in beam steering in different directions. The inverted L-shaped stubs were introduced in the ground which provided reasonable impedance matching for all cases (C) of operating modes (M) along with good gain and beam shifting capability. These stubs are depicted in the back view of the antenna in Figure 1.

2.1. Switching Technique. For switching purposes, pin diodes (SMP1345-079LF) are used, as they behave like a variable resistor in the radio frequency $(\mathrm{RF})$ range. These pin diodes provide open and the short circuit behavior at their respective insertion positions, which thus vary the effective resonant length of the antenna and hence result in reconfiguration of the antenna's operating frequency and radiation pattern. The equivalent circuits for both on and off states of pin-diode switches are shown in Figure 2. For the on state, it is simply an RL series circuit, having a low-value resistor 


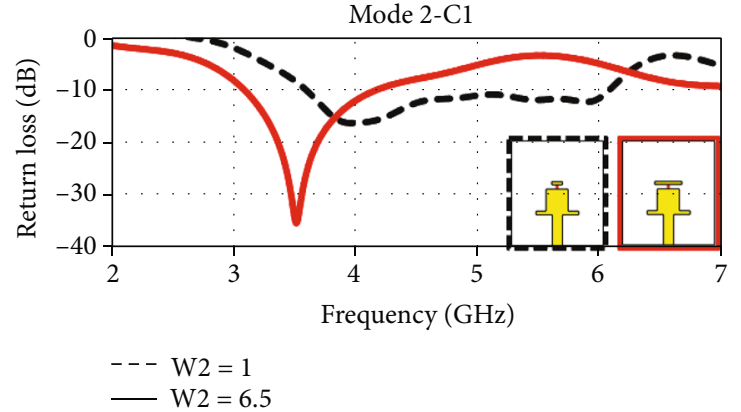

(a)

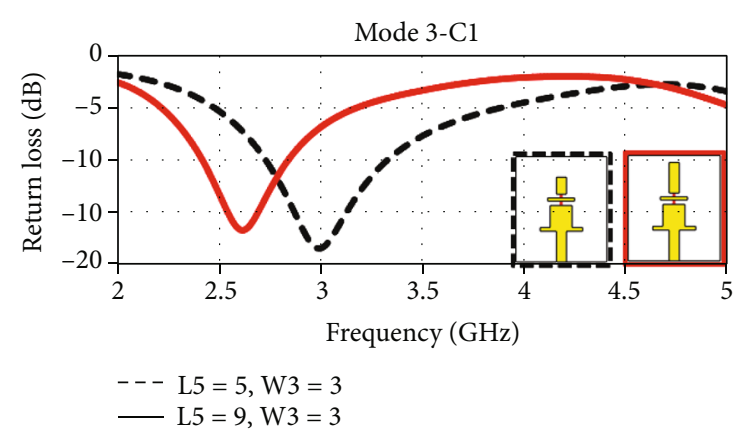

(b)

Figure 6: Design evolution of mode 2-C1 and mode 3-C1.

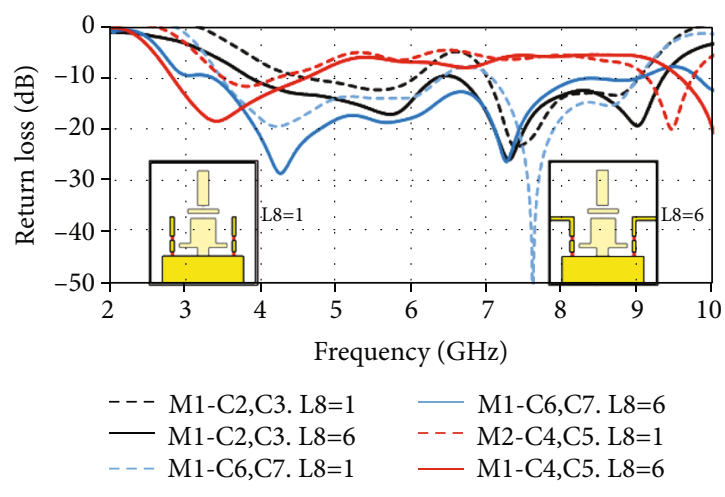

(a)

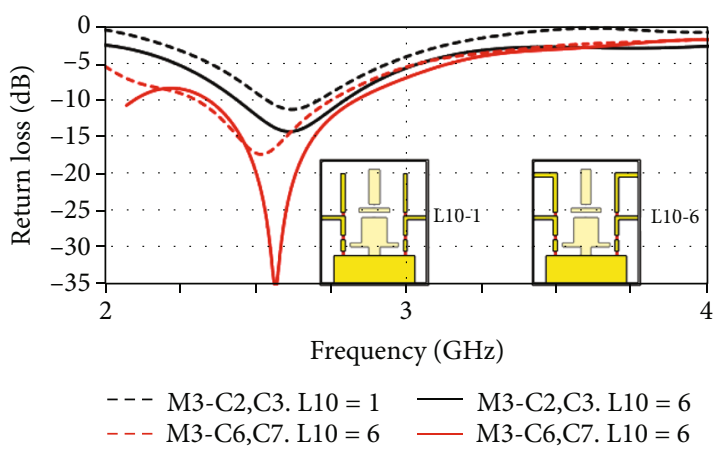

(b)

Figure 7: Design evolution of stubs.

" $R_{\mathrm{L}}$ " and an inductor " $L$." In the off state, it is equivalent to an RLC circuit, having an inductor " $L$ " in parallel with a highvalue resistor " $R_{\mathrm{H}}$ " and a capacitor " $C$."

A pin diode of model Skyworks SMP1345-079LF is used in this work. According to its datasheet, it can be modeled in CST as $R_{\mathrm{L}}=1.5 \Omega, L=0.7 \mathrm{nH}$, and $C=0.15 \mathrm{pF}$.

In the measurement step, the biasing circuit is introduced on the back side of the antenna for operating the pin diode in real time, as depicted in Figure 3.

Table 2 explains the switching configurations for all operating modes and their respective cases (C).

2.2. Evolution of Antenna's Design. The evolution of the proposed antenna's design involves several steps as depicted in Figure 4. All steps along with their return loss characteristic are illustrated in Figures 5-7. For achieving mode 1-C1, a monopole antenna excited with a microstrip feedline was designed to cover the $5.0-6.30 \mathrm{GHz}$ frequency band. For achieving better bandwidth and enhanced impedance matching for the intended resonant bands, the parameters $\mathrm{W} 1$ and $\mathrm{Wx}$ were increased, i.e., $\mathrm{W} 1=3-6.5 \mathrm{~mm}$ and $\mathrm{Wx}=0.5-3 \mathrm{~mm}$, as shown in Figure 5.

For mode 2-C1, a parasitic patch was introduced, connected in cascade with the primary radiator. It may be noted that the values of $\mathrm{W} 1$ and $\mathrm{Wx}$ were kept constant in this mode, equal to $6.5 \mathrm{~mm}$ and $3 \mathrm{~mm}$, respectively. At width $\mathrm{W}$ $2=1 \mathrm{~mm}$, the antenna was covering the impedance band-

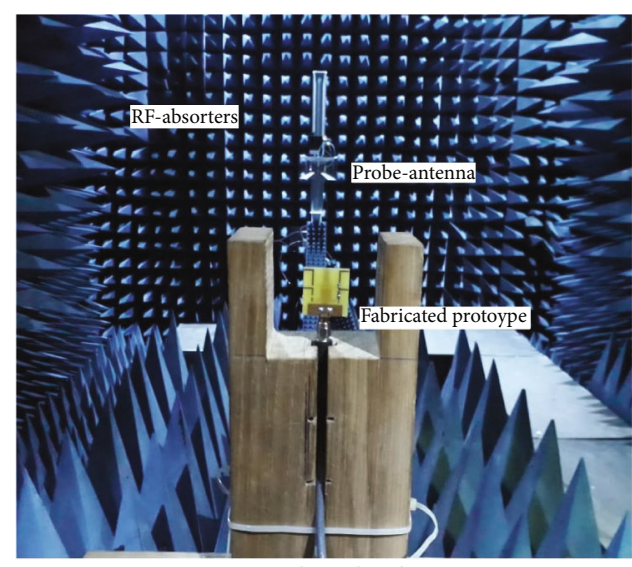

Anechoic chamber

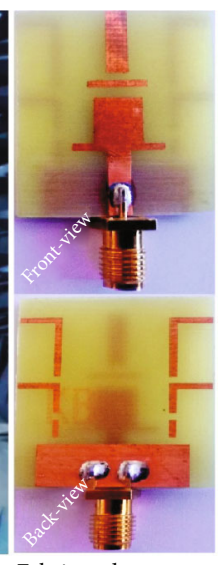

Fabricated prototype
FIgURE 8: Experimental setup for radiation pattern measurement under mode 1 -case 1 .

width of 3.6-6.1 GHz. For achieving the intended band of $3.5 \mathrm{GHz}$, the width $\mathrm{W} 2$ was increased from $1 \mathrm{~mm}$ to $2.5 \mathrm{~mm}$ as shown in Figure 6(a). For mode 3-C1, another parasitic patch was connected to the first one, as shown in Figure 6(b). The intended band of $2.6 \mathrm{GHz}$ was achieved by increasing the length L5 of the parasitic patch up to $9 \mathrm{~mm}$.

For achieving pattern reconfigurability, stubs were introduced on the backside layer of the antenna, and each stub was connected to the ground plane. The effect of these stubs on 

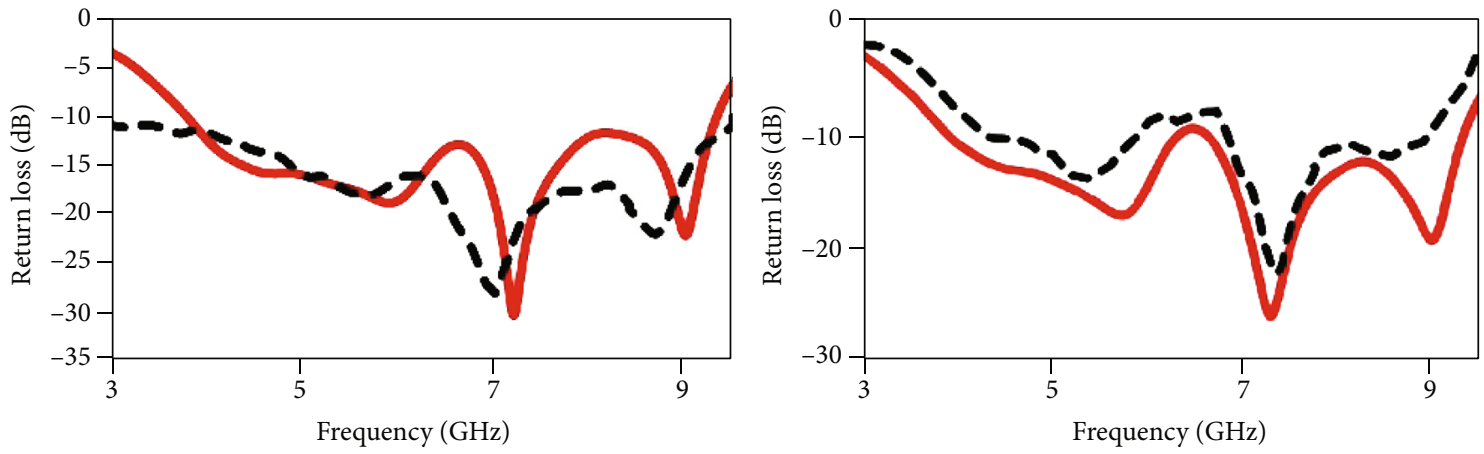

- M1-C1

- - M1-C1

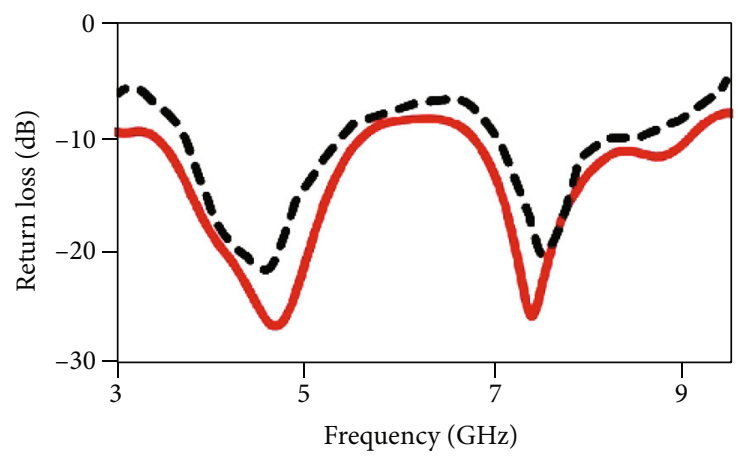

- M1-C4,C5

- - - M1-C4,C5

- Simulated

- - - Measured

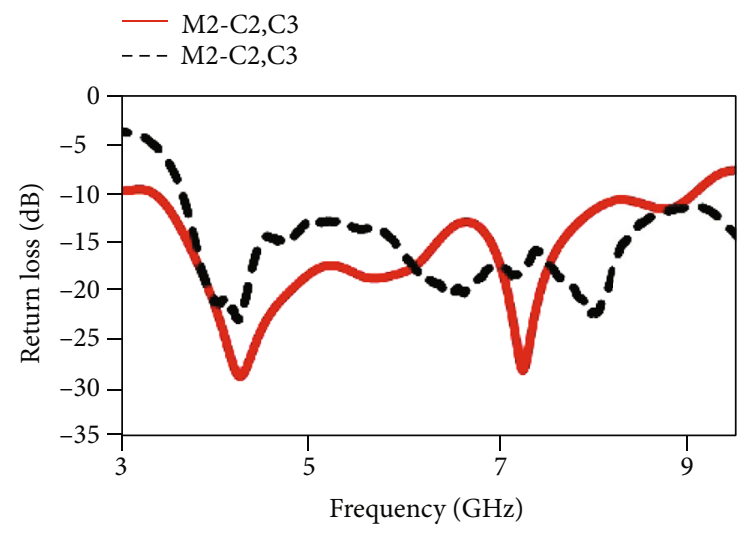

- M1-C6,C7

- - - M1-C6,C7

FIgURE 9: Simulated vs. measured return loss for cases of mode 1.
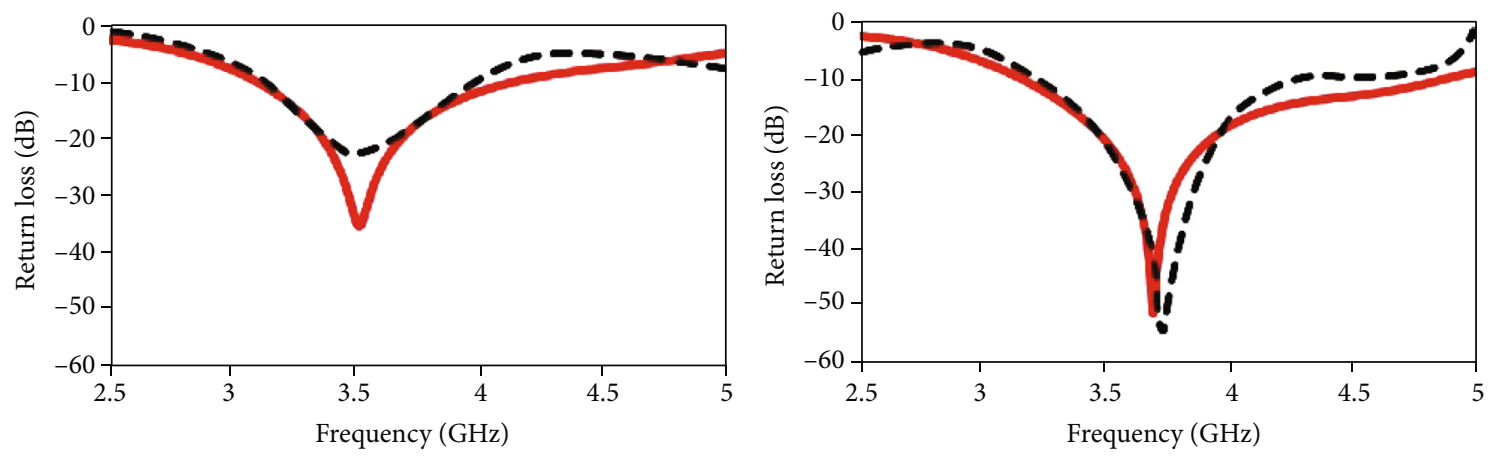

- M2-C1

- - M2-C1

- M2-C2,C3

- - - M2-C2,C3

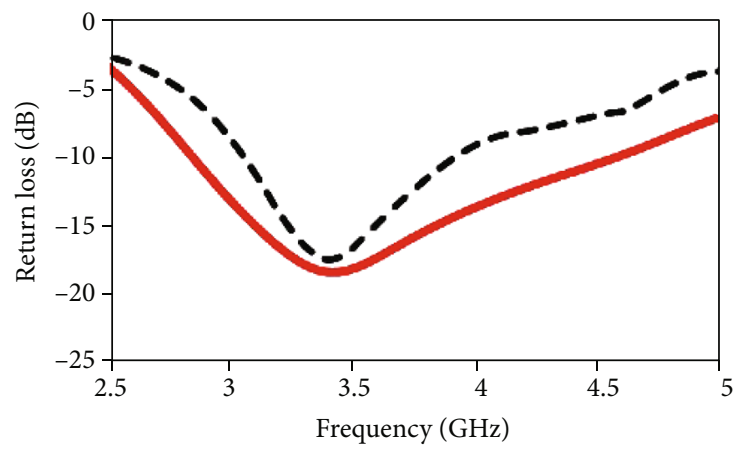

$\begin{array}{rr}\text { M2-C4-C5 } & \text { Simulated } \\ --- \text { M2-C4-C5 } & -- \text { Measured }\end{array}$

FIgURE 10: Simulated vs. measured return loss for cases of mode 2. 

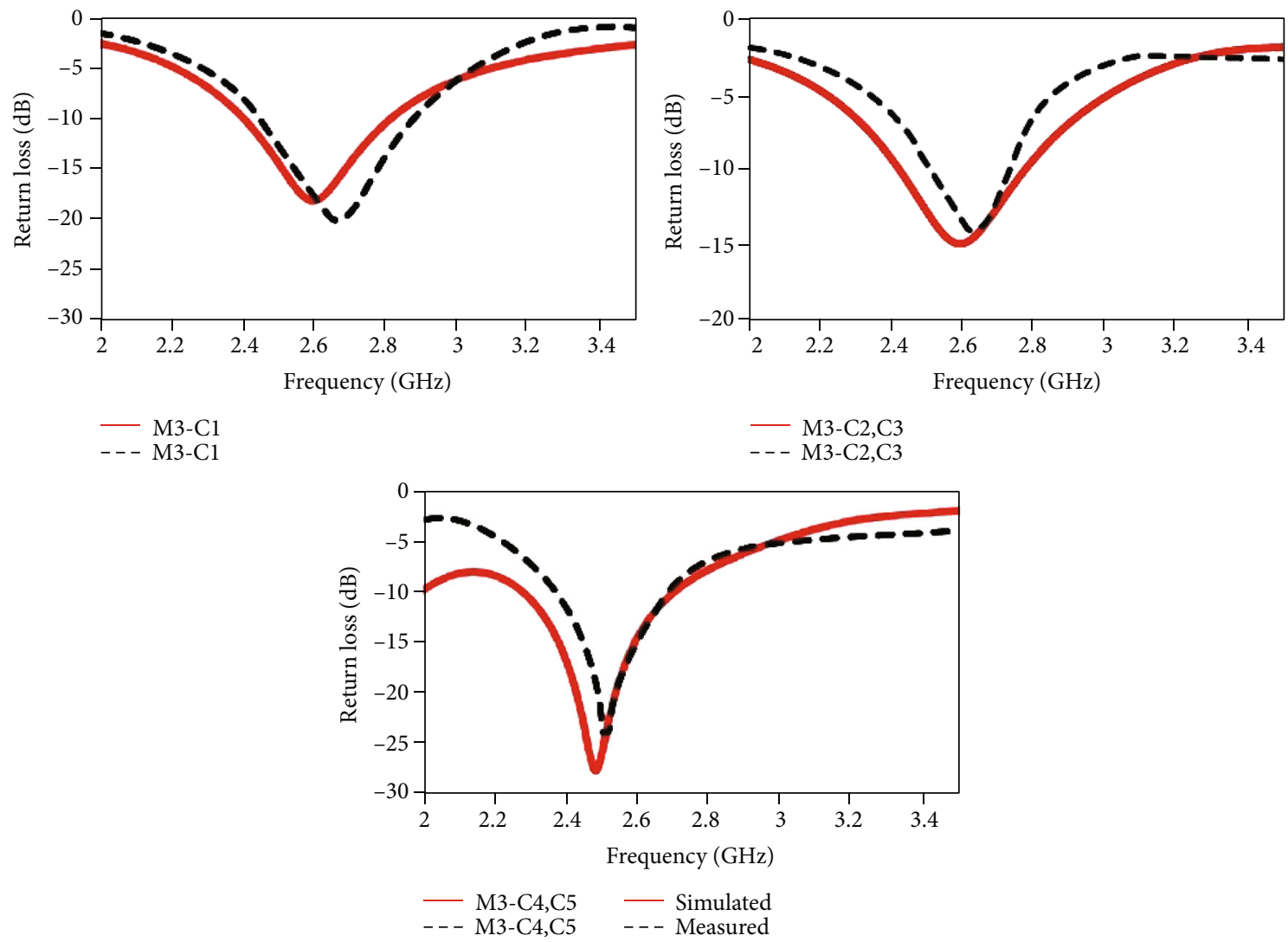

FIgURE 11: Simulated vs. measured return loss for cases of mode 3.
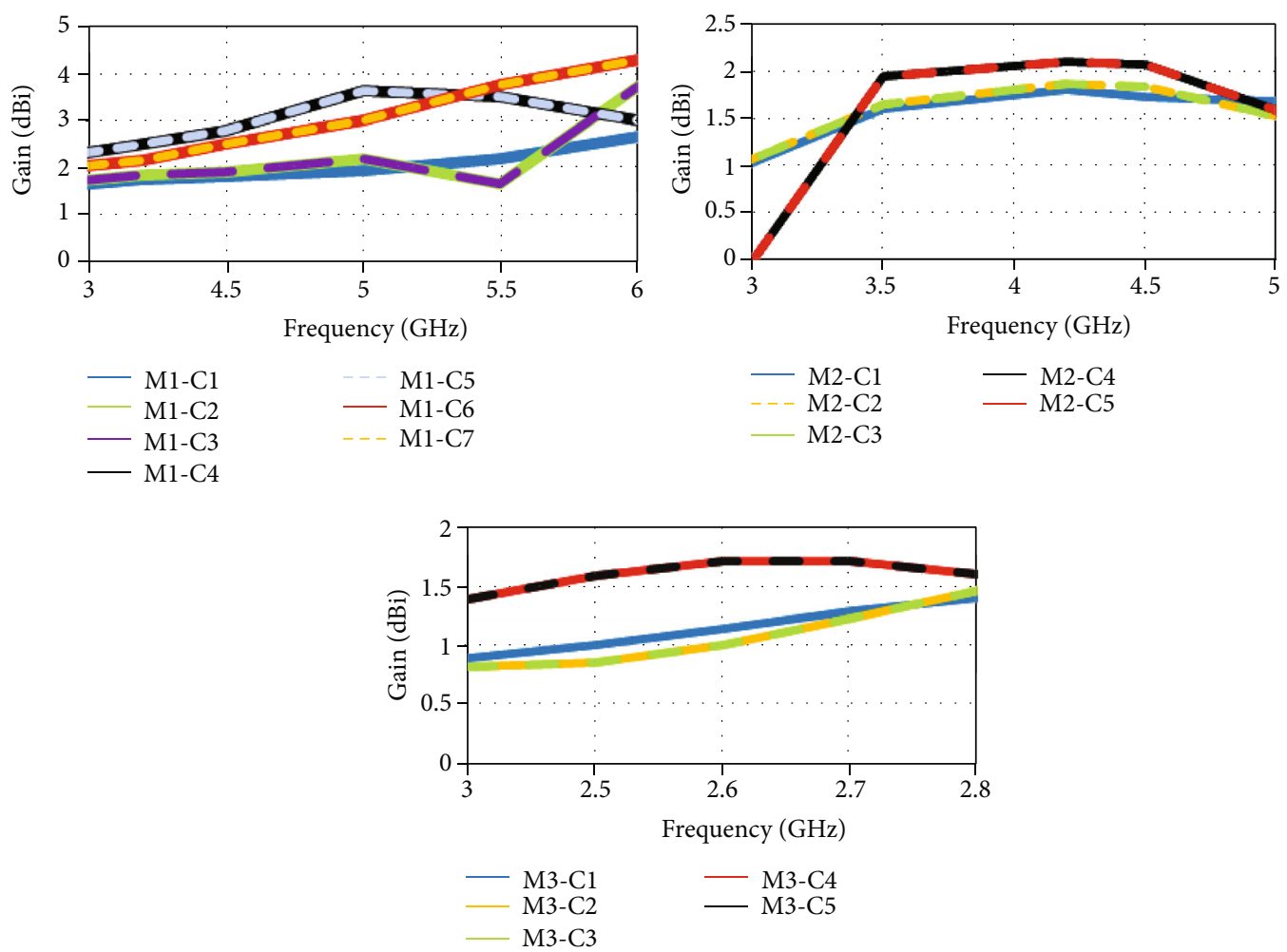

FIgURE 12: Gain over frequency plots for all operating modes and their cases. 


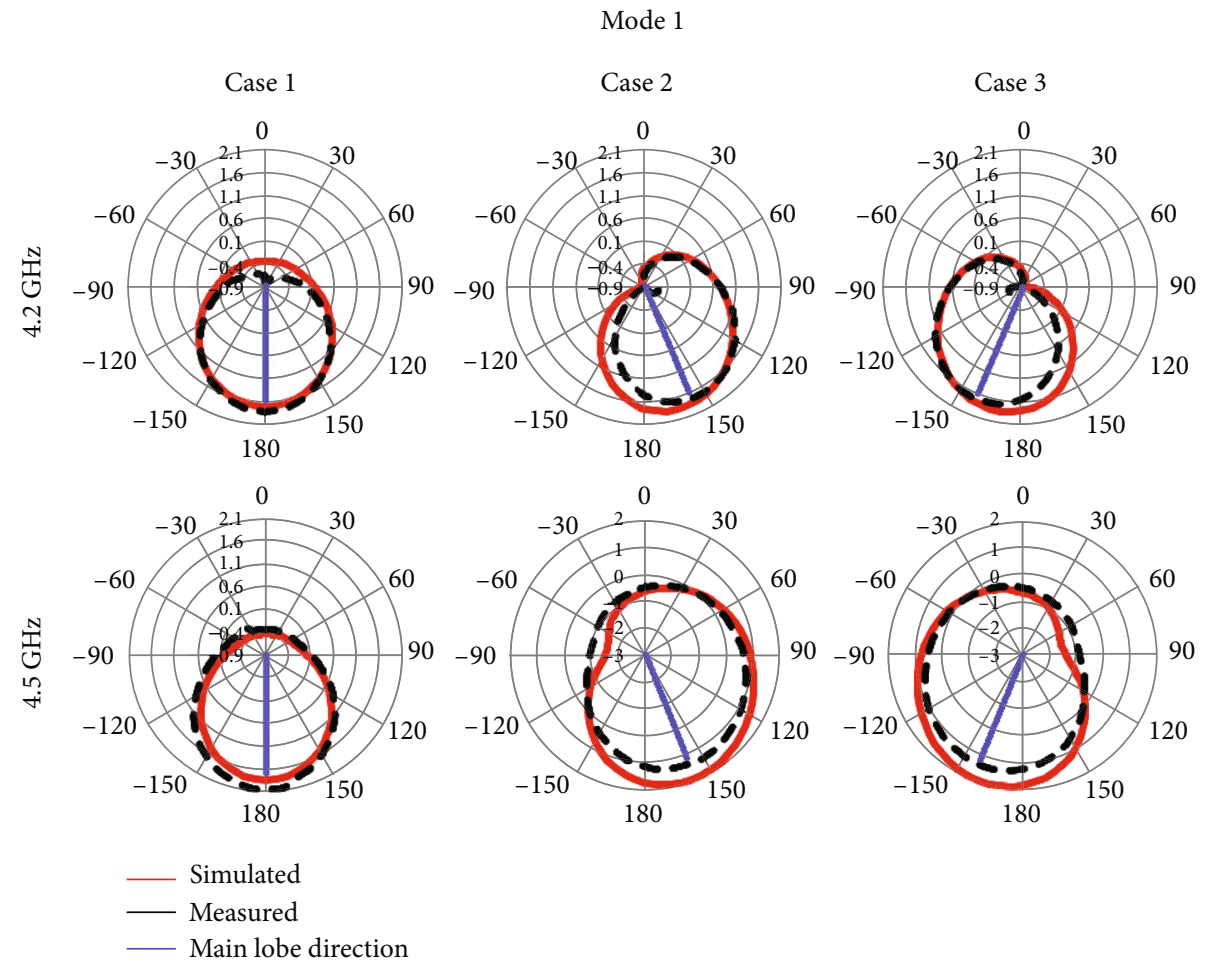

Figure 13: Polar plots (at phi $=0, x-z$ plane) for cases $1-3$ of mode 1 for $4.2 \mathrm{GHz}$ and $4.5 \mathrm{GHz}$.
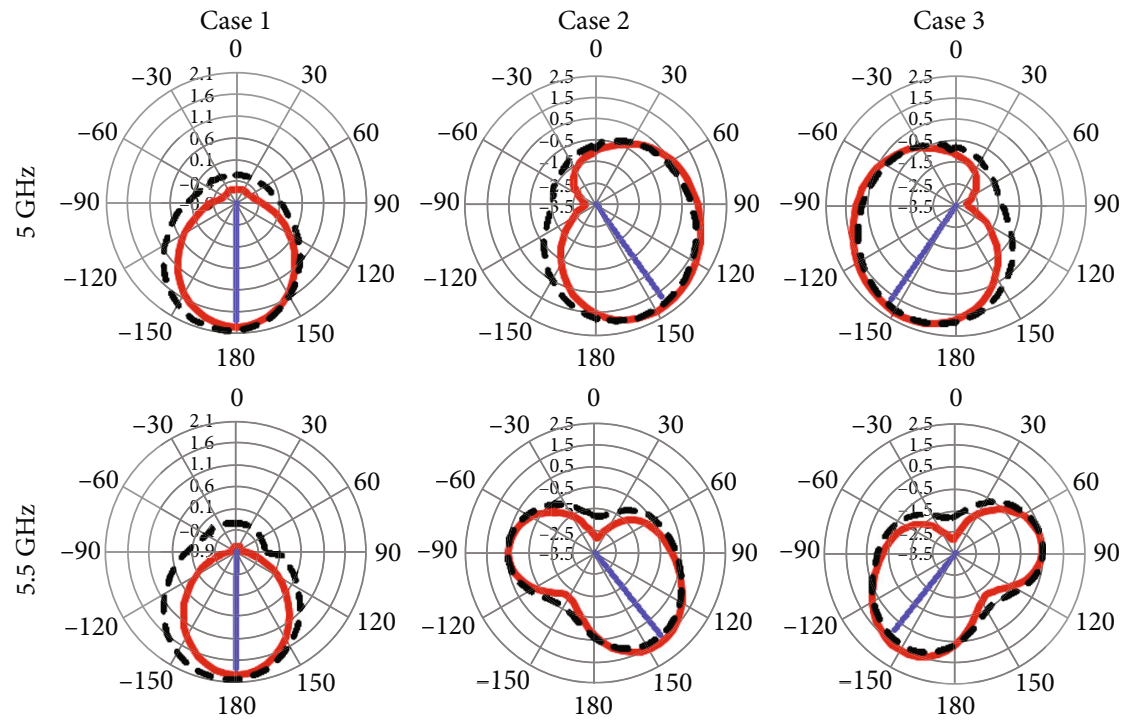

_ Simulated

- - - Measured

Main lobe direction

Figure 14: Polar plots (at phi $=0, x-z$ plane) for cases $1-3$ of mode 1 for $5 \mathrm{GHz}$ and $5.5 \mathrm{GHz}$.

the return loss characteristic of various cases of operating modes was analyzed. For cases 2 to 7 of mode 1 and cases 2 to 5 of mode 2, first, the I-shaped stubs were introduced (with $\mathrm{L} 8=1 \mathrm{~mm}$ ) which resulted in impedance mismatch for various cases of these modes. Therefore, inverted L-shaped stubs were achieved by increasing the length L8 up to $6 \mathrm{~mm}$ which provided reasonable impedance matching for all cases of these modes as shown in Figure 7(a). Similarly, for cases 2 to 5 of mode 3 , the impedance matching was achieved by increasing the L10 up to $6 \mathrm{~mm}$ as demonstrated in Figure 7(b). A sketch of the entire evolution process adopted in the design of the proposed antenna is illustrated in Figure 3. 
Mode 1
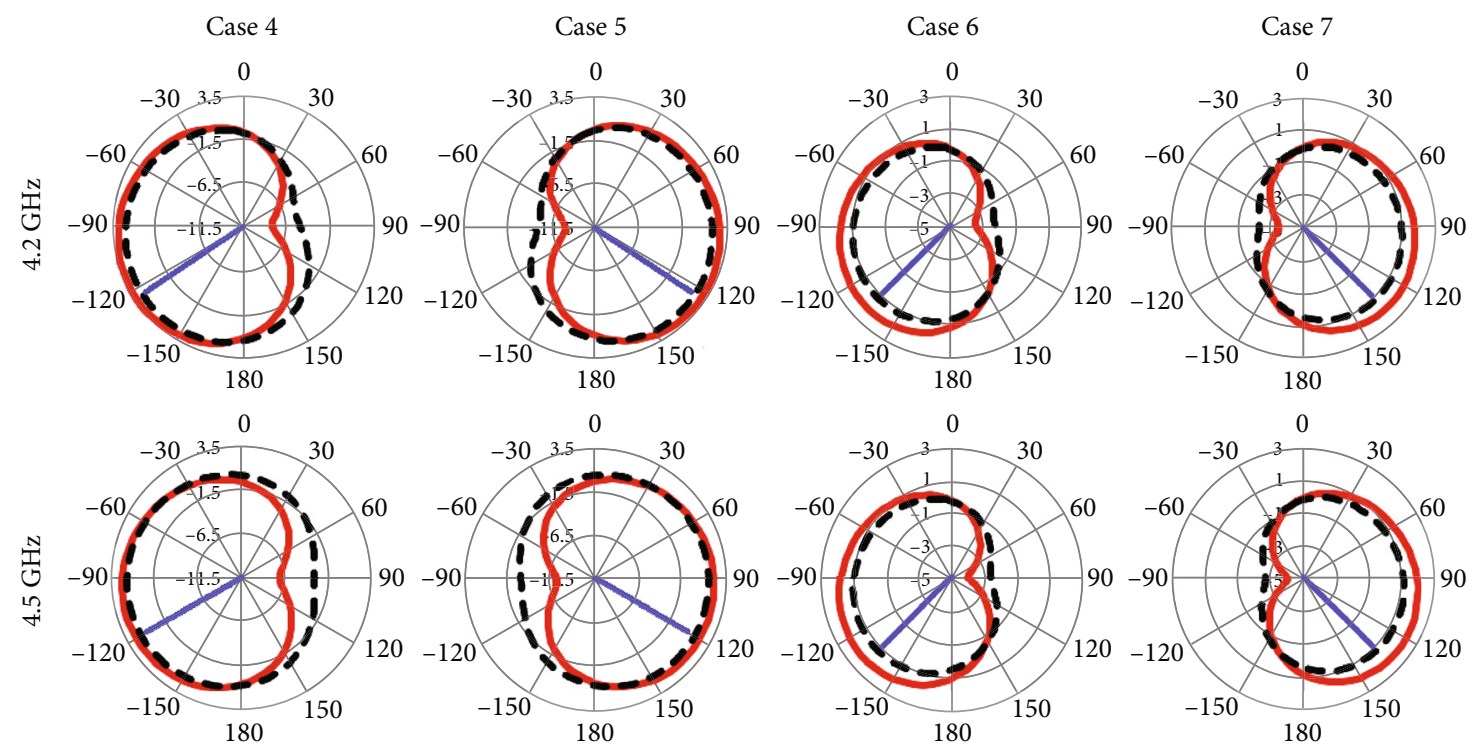

\section{_ Simulated \\ - - - Measured \\ — Main lobe direction}

Figure 15: Polar plots (at phi $=0, x-z$ plane) for cases $4-7$ of mode 1 for $4.2 \mathrm{GHz}$ and $4.5 \mathrm{GHz}$.

Mode 1
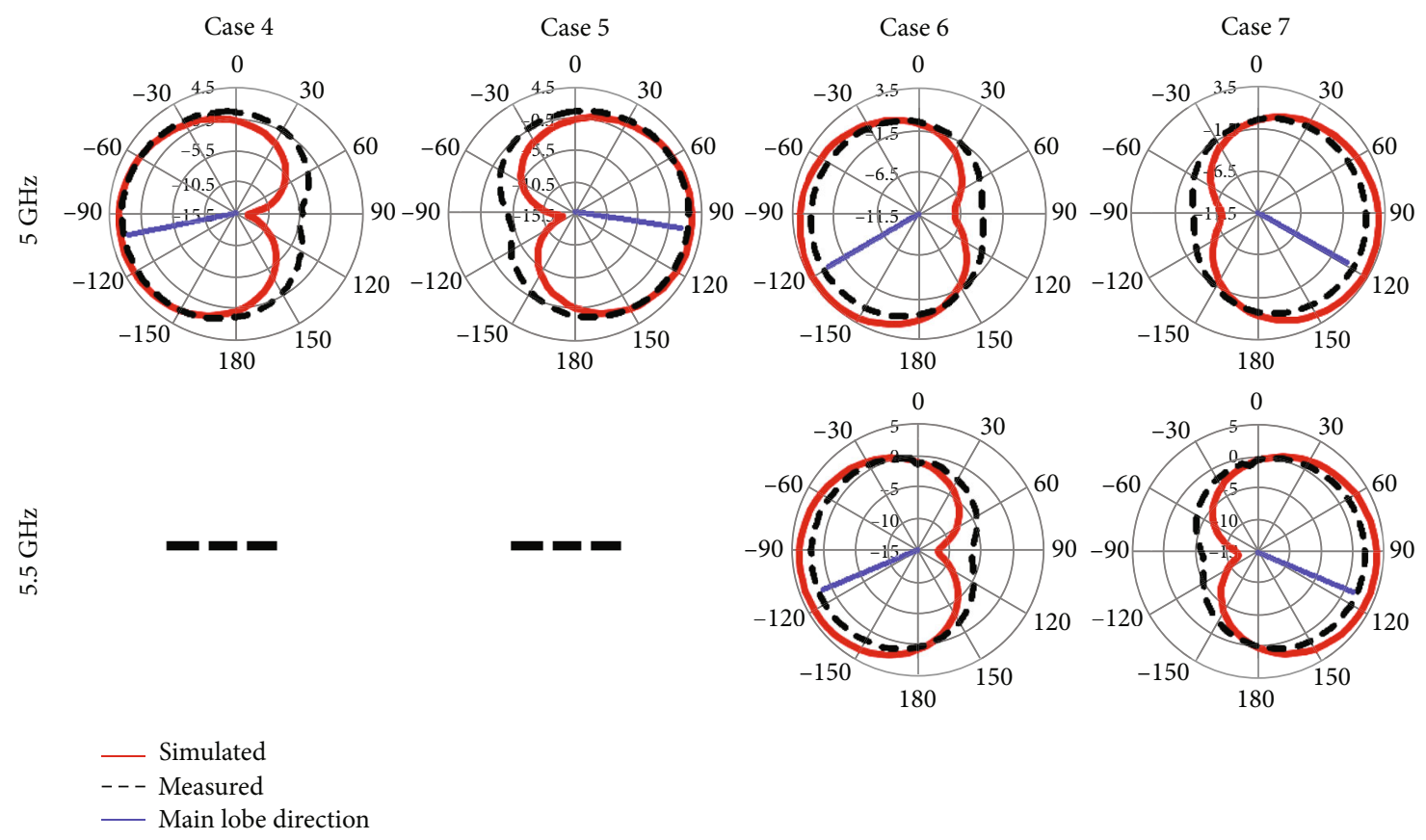

FIgURE 16: Polar plots (at phi $=0, x-z$ plane) for cases $4-7$ of mode 1 for $5 \mathrm{GHz}$ and $5.5 \mathrm{GHz}$.

\section{Experimental Results and Analysis}

The proposed antenna is simulated, and its performance is analyzed using CST Microwave Studio. The designed antenna is operating at three different modes. Each mode selects different frequencies and has several cases for pattern reconfiguration over those selected frequencies. The measurement setup and photographs of fabricated prototype are depicted in Figure 8. The graphs of return loss in mode 1, mode 2, and mode 3 are depicted in Figures 9, 10, and 11, respectively, for the mentioned switching cases. The gain vs. frequency plots are illustrated in Figure 12 for the three 

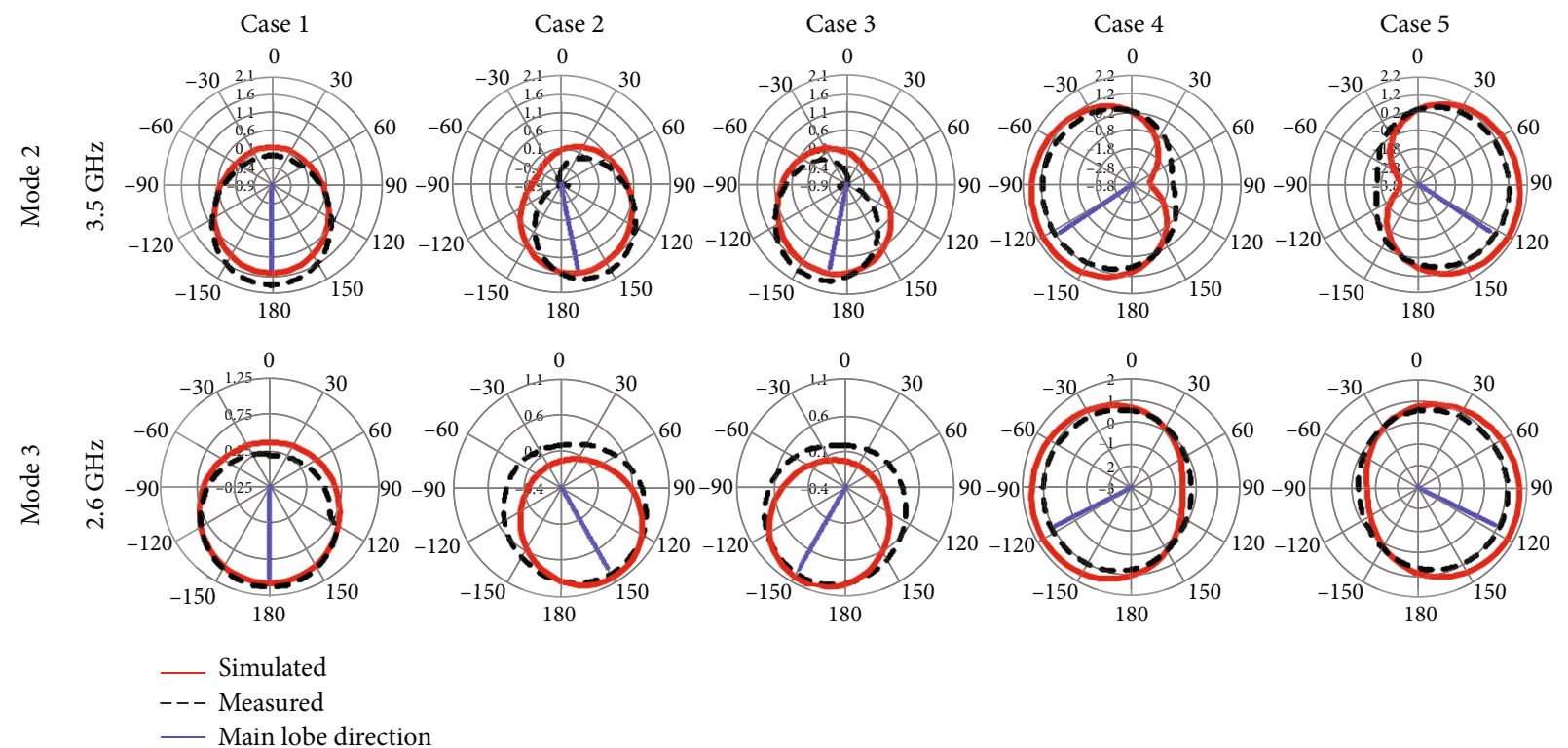

Figure 17: Polar plots (at phi $=0, x-z$ plane) of mode 2 and mode 3.

switching modes. The radiation pattern for the three modes is outlined in Figures 13-17 whereas the surface current distributions are displayed in Figures 18, 19, and 20, respectively, for the three switching modes. It is worth mentioning that the average radiation efficiencies of the antenna in mode 1 , mode 2 , and mode 3 are 75,77 , and $78 \%$, respectively.

3.1. Operation in Mode 1. When all switches are off, the designed antenna operates at the $1^{\text {st }}$ case of mode 1 , covering a wide range of frequencies $3.82-9.32 \mathrm{GHz}$. In this band, at the selected frequencies of $4.2 \mathrm{GHz}, 4.5 \mathrm{GHz}, 5 \mathrm{GHz}$, and $5.5 \mathrm{GHz}$, the antenna radiates by directing the main beam of the $H$-plane pattern $(\mathrm{phi}=0)$ at $180^{\circ}$. When switch $\mathrm{S} 6$ is on, the $2^{\text {nd }}$ case of mode 1 is selected, and the antenna operates at dual bands of $3.86-6.31 \mathrm{GHz}$ and $6.53-9.30 \mathrm{GHz}$ and steers the beam at $4.2 \mathrm{GHz}, 4.5 \mathrm{GHz}, 5 \mathrm{GHz}$, and $5.5 \mathrm{GHz}$ along $+165^{\circ},+160^{\circ},+147^{\circ}$, and $+145^{\circ}$, respectively. When S4 is on, the antenna switches to the $3^{\text {rd }}$ case of mode 1 , covering the abovementioned frequency bands, and steers the beam along $-165^{\circ},-160^{\circ},-147^{\circ}$, and $-145^{\circ}$ for respective operating frequencies. The antenna operates at the $4^{\text {th }}$ case of mode 1 when switches S4, S5, and S6 are on. In this case, the antenna covers two bands of $3.37-5.50 \mathrm{GHz}$ and $6.72-9.02 \mathrm{GHz}$ and steers the beam for $4.2 \mathrm{GHz}, 4.5 \mathrm{GHz}$, and $5 \mathrm{GHz}$ in three different directions of $-125^{\circ},-120^{\circ}$, and $-109^{\circ}$, respectively. When switches S3, S4, and S6 are on, the antenna operates at the $5^{\text {th }}$ case of its mode 1 , covering the same dual bands of case 4 , and steers the beam along $+125^{\circ},+120^{\circ}$, and $+109^{\circ}$ for $4.2 \mathrm{GHz}, 4.5 \mathrm{GHz}$, and $5 \mathrm{GHz}$, respectively. The $6^{\text {th }}$ case of mode 1 is selected when switches S5 and S6 are on. In this case, the antenna again covers a single wideband of $3.28-9.03 \mathrm{GHz}$ and shifts the beam at $4.2 \mathrm{GHz}, 4.5 \mathrm{GHz}$, $5 \mathrm{GHz}$, and $5.5 \mathrm{GHz}$ frequencies along $-130^{\circ},-130^{\circ},-120^{\circ}$, and $-115^{\circ}$, respectively. The antenna shifts its operation to the $7^{\text {th }}$ case of mode 1 , when switches S3 and S4 are on. The antenna covers the same range of frequencies as it

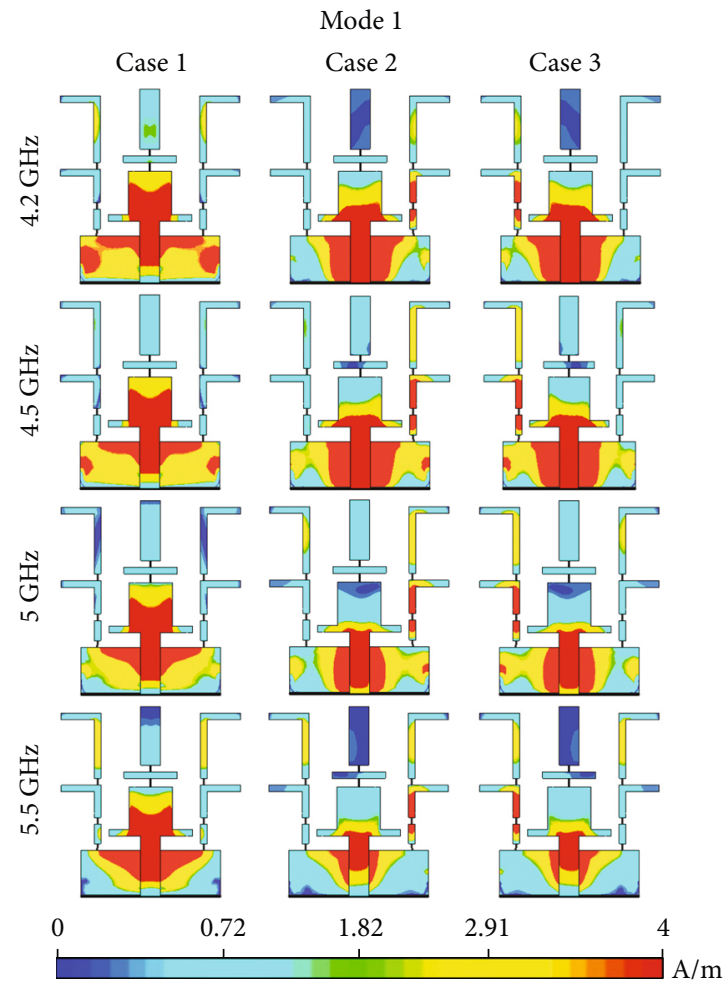

FIGURE 18: Surface currents for case 1, case 2, and case 3 of mode 1.

covers in the $6^{\text {th }}$ case and steers the beam in $-130^{\circ},-130^{\circ}$, $-120^{\circ}$, and $-115^{\circ}$ for $4.2 \mathrm{GHz}, 4.5 \mathrm{GHz}, 5 \mathrm{GHz}$, and $5.5 \mathrm{GHz}$ frequencies, respectively.

3.2. Operation in Mode 2. When switch S1 is on, the mode of antenna changes to mode 2 and the operating frequency of $3.5 \mathrm{GHz}$ is selected. In the $1^{\text {st }}$ case of mode 2 , the antenna gives a $-10 \mathrm{~dB}$ driving point impedance bandwidth within 


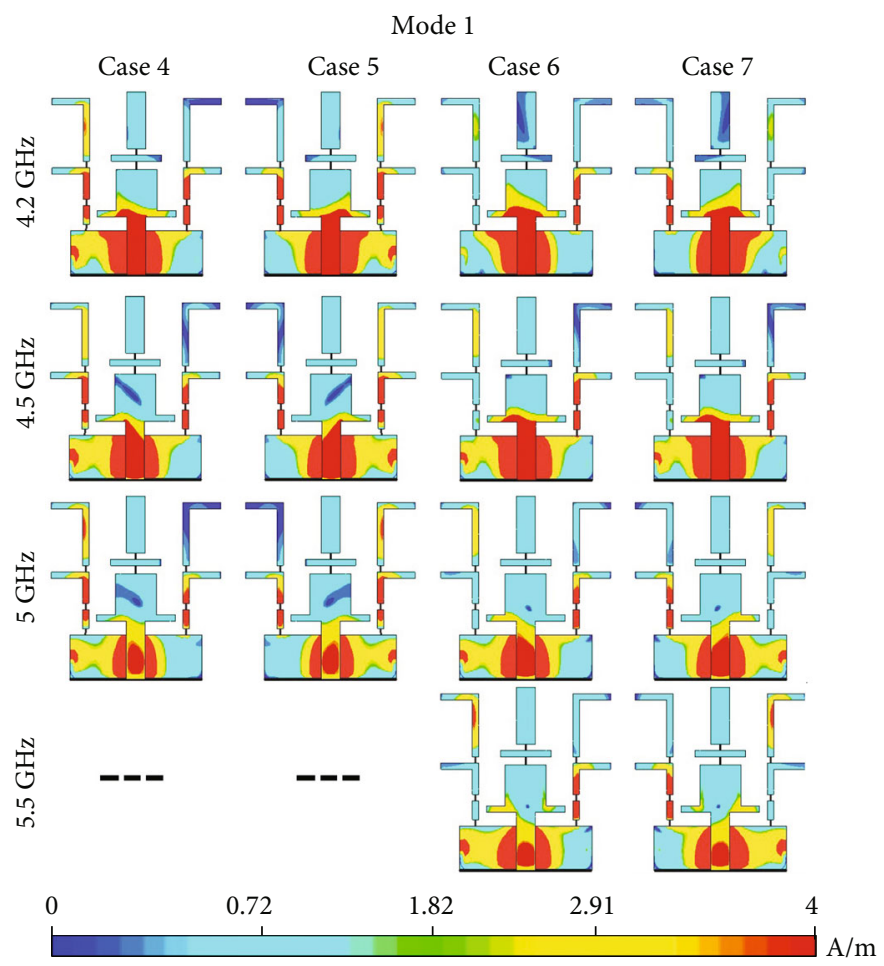

Figure 19: Surface currents for case 4, case 5, case 6, and case 7 of mode 1.

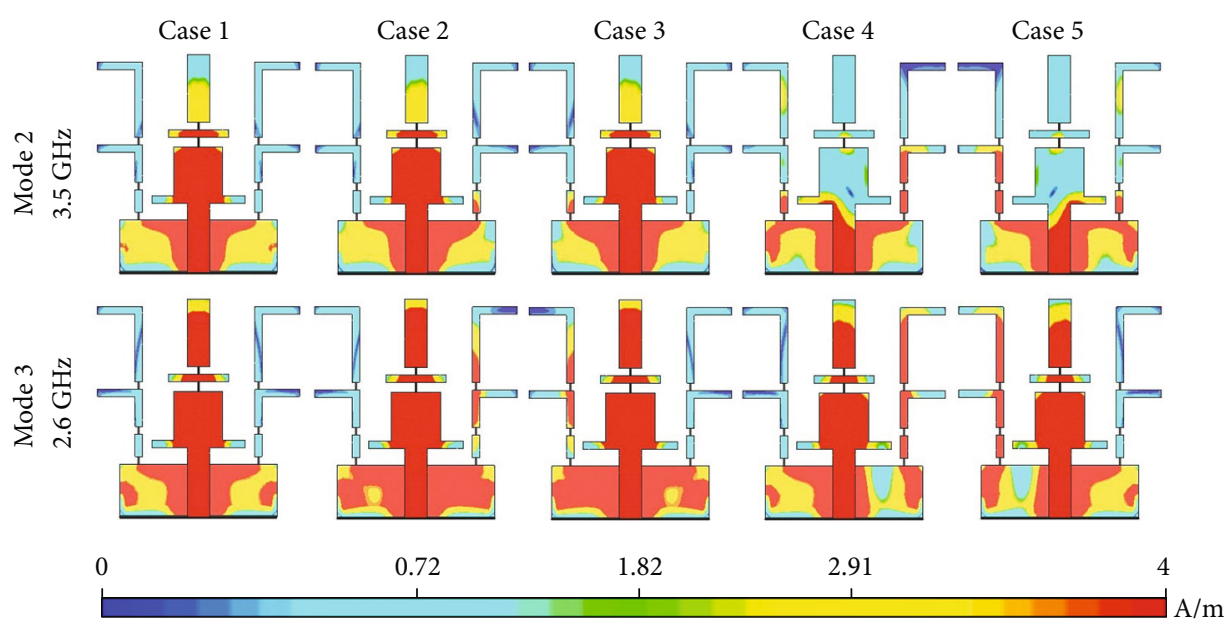

FIGURE 20: Surface currents of mode 2 and mode 3.

the frequency range of 3.09-4.17 GHz and directs the beam in $180^{\circ}$ (at phi $\left.=0\right)$. When switches S1 and S5 are on, the $2^{\text {nd }}$ case is selected, and when $\mathrm{S} 1$ and $\mathrm{S} 3$ are on, the $3^{\text {rd }}$ case is selected and the antenna covers the frequency band of 3.14$4.88 \mathrm{GHz}$ in both cases. The main beam of the antenna is directed for $3.5 \mathrm{GHz}$ along $+160^{\circ}$ in the $2^{\text {nd }}$ case and along $-160^{\circ}$ in the $3^{\text {rd }}$ case. Similarly, when switches S1, S3, S5, and S6 are on, the 4th case is selected and when S1, S3, S4, and S5 are on, the $5^{\text {th }}$ case is selected. In both cases (cases $4^{\text {th }}$ and $5^{\text {th }}$ ), the antenna covers a range of frequencies, 2.83-4.59 GHz, and directs the beam for $3.5 \mathrm{GHz}$ in $-122^{\circ}$ in the $4^{\text {th }}$ case and $+122^{\circ}$ in the $5^{\text {th }}$ case.
3.3. Operation in Mode 3. When switches S1 and S2 are on, the antenna operates at the $1^{\text {st }}$ case of mode 3 . The proposed antenna operates at $2.6 \mathrm{GHz}$, covering a band of 2.40 $2.81 \mathrm{GHz}$, and directs the beam in $180^{\circ}$ in this case. When switches S6 and S8 are on along with S1 and S2, the operation of the antenna shifts to the $2^{\text {nd }}$ case of mode 3 . In this case, the antenna covers a band of $2.42-2.77 \mathrm{GHz}$ and shifts the beam in $+150^{\circ}$ for $2.6 \mathrm{GHz}$ frequency. The $3^{\text {rd }}$ case of mode 3 is selected when switches S1, S2, S4, and S7 are on. The designed antenna covers the same band $(2.42-2.77 \mathrm{GHz})$ and shifts the beam for $2.6 \mathrm{GHz}$ along $-150^{\circ}$. When switches $\mathrm{S} 1, \mathrm{~S} 2, \mathrm{~S} 5, \mathrm{~S} 6$, and S8 are on, the $4^{\text {th }}$ case is selected while the 
TABLe 3: Performance summary of the antenna in mode 1.

\begin{tabular}{|c|c|c|c|c|c|c|}
\hline Mode no. & Special cases & $\begin{array}{c}\text { Operating } \\
\text { frequency }(\mathrm{GHz})\end{array}$ & $\begin{array}{c}\text { Bandwidth } f_{l}-f_{u} \\
(\mathrm{MHz})\end{array}$ & $\begin{array}{l}\text { Gain } \\
(\mathrm{dBi})\end{array}$ & $\begin{array}{c}\text { Beam direction } \\
\text { at phi }=0^{\circ}\end{array}$ & $\begin{array}{l}\text { Beam shifting } \\
\text { angle }\end{array}$ \\
\hline \multirow{26}{*}{1} & \multirow{4}{*}{ (1) When all switches are off } & 4.2 & \multirow{4}{*}{$3.82-9.32(5500)$} & 1.80 & $180^{\circ}$ & $0^{\circ}$ \\
\hline & & 4.5 & & 1.85 & $180^{\circ}$ & $0^{\circ}$ \\
\hline & & 5 & & 1.97 & $180^{\circ}$ & $0^{\circ}$ \\
\hline & & 5.5 & & 2.25 & $180^{\circ}$ & $0^{\circ}$ \\
\hline & \multirow{4}{*}{ (2) When only S6 is on } & 4.2 & \multirow{4}{*}{$\begin{array}{c}3.86-6.31(2450) / \\
6.53-9.30(2770)\end{array}$} & 1.87 & $+165^{\circ}$ & $+15^{\circ}$ \\
\hline & & 4.5 & & 1.95 & $+160^{\circ}$ & $+20^{\circ}$ \\
\hline & & 5 & & 2.3 & $+147^{\circ}$ & $+33^{\circ}$ \\
\hline & & 5.5 & & 1.7 & $+145^{\circ}$ & $+35^{\circ}$ \\
\hline & \multirow{4}{*}{ (3) When only S4 is on } & 4.2 & \multirow{4}{*}{$\begin{array}{c}3.86-6.31(2450) / \\
6.53-9.30(2770)\end{array}$} & 1.87 & $-165^{\circ}$ & $-15^{\circ}$ \\
\hline & & 4.5 & & 1.95 & $-160^{\circ}$ & $-20^{\circ}$ \\
\hline & & 5 & & 2.3 & $-147^{\circ}$ & $-33^{\circ}$ \\
\hline & & 5.5 & & 1.7 & $-145^{\circ}$ & $-35^{\circ}$ \\
\hline & \multirow{3}{*}{ (4) When S4, S5, and S6 are on } & 4.2 & \multirow{3}{*}{$\begin{array}{l}3.37-5.50(2130) / \\
6.72-9.02(2300)\end{array}$} & 2.51 & $-125^{\circ}$ & $-55^{\circ}$ \\
\hline & & 4.5 & & 2.81 & $-120^{\circ}$ & $-60^{\circ}$ \\
\hline & & 5 & & 3.66 & $-109^{\circ}$ & $-71^{\circ}$ \\
\hline & \multirow{3}{*}{ (5) When S3, S4, and S6 are on } & 4.2 & \multirow{3}{*}{$\begin{array}{c}3.37-5.50(2130) / \\
6.72-9.02(2300)\end{array}$} & 2.51 & $+125^{\circ}$ & $+55^{\circ}$ \\
\hline & & 4.5 & & 2.81 & $+120^{\circ}$ & $+60^{\circ}$ \\
\hline & & 5 & & 3.66 & $+109^{\circ}$ & $+71^{\circ}$ \\
\hline & \multirow{4}{*}{ (6) When S5 and S6 are on } & 4.2 & \multirow{4}{*}{$3.28-9.03(5750)$} & 2.2 & $-130^{\circ}$ & $-50^{\circ}$ \\
\hline & & 4.5 & & 2.52 & $-130^{\circ}$ & $-50^{\circ}$ \\
\hline & & 5 & & 3.04 & $-120^{\circ}$ & $-60^{\circ}$ \\
\hline & & 5.5 & & 3.8 & $-115^{\circ}$ & $-65^{\circ}$ \\
\hline & \multirow{4}{*}{ (7) When S3 and S4 are on } & 4.2 & \multirow{4}{*}{$3.28-9.03(5750)$} & 2.2 & $+130^{\circ}$ & $+50^{\circ}$ \\
\hline & & 4.5 & & 2.52 & $+130^{\circ}$ & $+50^{\circ}$ \\
\hline & & 5 & & 3.04 & $+120^{\circ}$ & $+60^{\circ}$ \\
\hline & & 5.5 & & 3.8 & $+115^{\circ}$ & $+65^{\circ}$ \\
\hline
\end{tabular}

$5^{\text {th }}$ case is selected when switches S1, S2, S3, S4, and S7 are on. The antenna operates in the same frequency band of 2.26$2.70 \mathrm{GHz}$ in the both the cases and shifts the beam along $-119^{\circ}$ in the $4^{\text {th }}$ case and $+119^{\circ}$ along the $5^{\text {th }}$ case for $2.6 \mathrm{GHz}$.

The direction of the main beam along with the peak gain is summarized in Table 3. The "beam shifting angle" in Table 3 shows how much the antenna shifts the beam (in degrees) for each operating frequency. The return losses are analyzed for all cases of operating modes. From the return loss plots, it is evident that the antenna has good impedance matching for all intended frequencies at all respective cases.

The comparisons between simulated and measured return losses and polar plots are shown in Figures 9-11 and Figures 13-17, respectively. The comparison shows a good agreement between measured and simulated results. All the respective results are measured at NUST (National University of Science and Technology) in the antenna measurement laboratory.

The surface current distribution for all operating modes is depicted in Figures 18-20. These surface currents provide the information about contributing resonant areas of the antenna for each case of operating modes, thus helping in understanding the operation of the antenna at different operating states. The surface currents of case 1 of all modes are related to frequency reconfigurability and show the contributing resonant length for respective operating frequencies. Case 1 of all operating modes clearly indicates that the contributing resonant length is reduced as the resonant frequency increases, thus proving the inverse relation of frequency with resonant length. All other cases are related with pattern reconfigurability and give information about the contributing lengths of stubs for various pattern reconfiguration operations. Cases 2 to 7 of mode 1 and cases 2 to 5 of mode 2 and 3 show the active portions of stubs at different cases which result in beam steering inn different directions. Relating the surface currents with polar plots provides clear understanding about the beam steering phenomenon. For understanding the complete reconfigurability operation, cases 1-5 of mode 1 are considered for $4.2 \mathrm{GHz}$ frequency. In case 1 , the antenna is radiating in the direction of $180^{\circ}$ because the stubs do not contribute to beam steering operation. In case 2, when switch S6 is on, the surface currents indicate that the right-side stub comes in action and shifts the beam to $+165^{\circ}$. For case 3, when switch S4 is on, the surface current indicates that the left-side stub operates and shifts the beam to $-165^{\circ}$. In case 4 , when switches S4, S5, and S6 are on and in case 5, when switches S3, S4, and S6 are on, the distribution of surface currents is such that both 
TABle 4: Performance summary of the antenna in mode 2 and mode 3.

\begin{tabular}{|c|c|c|c|c|c|c|}
\hline $\begin{array}{l}\text { Mode } \\
\text { no. }\end{array}$ & Special cases & $\begin{array}{l}\text { Operating frequency } \\
(\mathrm{GHz})\end{array}$ & $\begin{array}{l}\text { Bandwidth } f_{l}-f_{u} \\
(\mathrm{MHz})\end{array}$ & $\begin{array}{l}\text { Gain } \\
(\mathrm{dBi})\end{array}$ & $\begin{array}{c}\text { Beam direction at } \\
\text { phi }=0^{\circ}\end{array}$ & $\begin{array}{l}\text { Beam shifting } \\
\text { angle }\end{array}$ \\
\hline \multirow{5}{*}{2} & (1) When only S1 is on & \multirow{5}{*}{3.5} & $3.09-4.17(1080)$ & 1.67 & $180^{\circ}$ & $0^{\circ}$ \\
\hline & (2) When S1 and S5 are on & & $3.14-4.88(1740)$ & 1.67 & $+160^{\circ}$ & $+20^{\circ}$ \\
\hline & (3) When S1 and S3 are on & & $3.14-4.88(1740)$ & 1.67 & $-160^{\circ}$ & $-20^{\circ}$ \\
\hline & (4) When S1, S3, S5, and S6 are on & & $2.83-4.59(1760)$ & 1.94 & $-122^{\circ}$ & $-58^{\circ}$ \\
\hline & (5) When S1, S3, S4, and S5 are on & & $2.83-4.59(1760)$ & 1.94 & $+122^{\circ}$ & $+58^{\circ}$ \\
\hline \multirow{5}{*}{3} & (1) When only S1 and S2 are on & \multirow{5}{*}{2.6} & $2.40-2.81(410)$ & 1.26 & $180^{\circ}$ & $0^{\circ}$ \\
\hline & (2) When S1, S2, S6, and S8 are on & & $2.42-2.77(350)$ & 1.11 & +150 & $+30^{\circ}$ \\
\hline & (3) When S1, S2, S4, and S7 are on & & $2.42-2.77(350)$ & 1.11 & -150 & $-30^{\circ}$ \\
\hline & (4) When S1, S2, S5, S6, and S8 are on & & $2.26-2.70(440)$ & 1.72 & -119 & $-61^{\circ}$ \\
\hline & (5) When S1, S2, S3, S4, and S7 are on & & $2.26-2.70(440)$ & 1.72 & +119 & $+61^{\circ}$ \\
\hline
\end{tabular}

TABLE 5: Performance comparison of the proposed antenna with other reported works.

\begin{tabular}{|c|c|c|c|c|c|c|}
\hline Ref & Size & $\begin{array}{l}\text { Number of } \\
\text { switches }\end{array}$ & $\begin{array}{c}\text { Number of operating } \\
\text { frequencies }\end{array}$ & $\begin{array}{l}\text { Max beam } \\
\text { number }\end{array}$ & $\begin{array}{l}\text { Bandwidth } \\
\text { (MHz) }\end{array}$ & Peak gains $(\mathrm{dBi})$ \\
\hline$[22]$ & $130 \times 160$ & 11 & 3 & 3 & $200 / 150 / 150$ & $5.6 / 4.6 / 3.3$ \\
\hline [23] & $160 \times 151$ & 2 & 2 & 2 & 730 & 9 \\
\hline$[24]$ & $120 \times 120$ & 12 & 2 & 3 & $63.47 / 102$ & $9.05 / 10.63$ \\
\hline [25] & $70 \times 70$ & 6 & 2 & 3 & NG & $5.08 / 7.0$ \\
\hline [26] & $50 \times 50$ & 4 & 4 & 3 & $180 / 200 / 180 / 200$ & $4 / 3.8 / 4.4 / 5$ \\
\hline [27] & $42 \times 44$ & 8 & 2 & 2 & $160 / 220$ & NG \\
\hline [28] & $40 \times 30$ & 4 & 2 & 3 & $400 / 500$ & $2.24 / 2.76$ \\
\hline $\begin{array}{l}\text { This } \\
\text { work }\end{array}$ & $31 \times 27$ & 8 & 6 & 7 & $410 / 1080 / 5500$ & $1.72 / 1.94 / 2.51 / 2.81 / 3.66 / 3.8$ \\
\hline
\end{tabular}

stubs are in excited and contribute in switching the beam to $-125^{\circ}$ in case 4 and $+125^{\circ}$ in case 5 . Similarly, the surface currents of all other cases of all modes clearly explain the pattern reconfiguration ability of the antenna.

The special cases for different switching modes and the performance parameters of the proposed antenna are summarized in Tables 3 and 4. The gain for all the bands is satisfactory for the intended application. The performance metrics of the proposed antenna are compared with the latest reported work in Table 5. The comparison table demonstrates that this antenna is relatively compact in size, with greater number of working bands, better gain, and better bandwidth.

\section{Conclusion}

A multiband compound reconfigurable antenna having both frequency reconfigurability and pattern reconfigurability is designed and experimentally validated in this paper. The compound reconfigurability is achieved using eight pindiode switches; two switches (S1 and S2) are for frequency reconfigurability, and the other six switches (S3, S4, S5, S6, S7, S8) control the beam steering. The antenna operates at three modes. Each mode selects different frequencies and has several cases for beam steering over the operating frequencies. The antenna covers a wideband of $3.09-4.17 \mathrm{GHz}$ in mode 1 (when all switches are off). In mode 2 (when only S1 is on) and mode 3 (when S1 and S2 are both on), the antenna operates at $3.5 \mathrm{GHz}$ and $2.6 \mathrm{GHz}$ bands, respectively. The simulated results show that the designed antenna can direct the beam in seven different directions for $4.2 \mathrm{GHz}$, $4.5 \mathrm{GHz}$, and $5 \mathrm{GHz}$ and in five distinct directions for $5.5 \mathrm{GHz}, 3.5 \mathrm{GHz}$, and $2.6 \mathrm{GHz}$ bands with an acceptable peak gain. The proposed antenna supports several sub-6 GHz $5 \mathrm{G}$ bands $(2.6 \mathrm{GHz}, 3.5 \mathrm{GHz}, 4.2 \mathrm{GHz}, 4.5 \mathrm{GHz}$, and $5 \mathrm{GHz}$ ). The antenna can be used in $5 \mathrm{G}$ mobile applications.

\section{Data Availability}

The data used to support the findings of this study are available from the corresponding author on request.

\section{Conflicts of Interest}

The authors declare that they have no conflicts of interest.

\section{Acknowledgments}

This research has been financially supported by the Research Council (TRC) of the Sultanate of Oman (agreement No. TRC/BFP/ASU/01/2018). 


\section{References}

[1] M. J. Marcus, "5G and IMT for 2020 and beyond [spectrum policy and regulatory issues]," IEEE Wireless Communications, vol. 22, no. 4, pp. 2-3, 2015.

[2] T. S. Rappaport, S. Sun, R. Mayzus et al., "Millimeter wave mobile communications for $5 \mathrm{G}$ cellular: it will work!," IEEE Access, vol. 1, pp. 335-349, 2013.

[3] M. Jenath and V. Nagarajan, "Review on frequency reconfigurable antenna for wireless applications," in 2017 International Conference on Communication and Signal Processing (ICCSP), pp. 2240-2245, Chennai, India, 2017.

[4] I. F. Akyildiz, W.-Y. Lee, M. C. Vuran, and S. Mohanty, "NeXt generation/dynamic spectrum access/cognitive radio wireless networks: a survey," Computer Networks, vol. 50, no. 13, pp. 2127-2159, 2006.

[5] J. Dong, Y. Li, and B. Zhang, "A survey on radiation pattern reconfigurable antennas," in 2011 7th International Conference on Wireless Communications, Networking and Mobile Computing, pp. 1-4, Wuhan, China, 2011.

[6] M. Borhani, P. Rezaei, and A. Valizade, "Design of a reconfigurable miniaturized microstrip antenna for switchable multiband systems," IEEE Antennas and Wireless Propagation Letters, vol. 15, pp. 822-825, 2016.

[7] S. W. Lee and Y. Sung, "Compact frequency reconfigurable antenna for LTE/WWAN mobile handset applications," IEEE Transactions on Antennas and Propagation, vol. 63, no. 10, pp. 4572-4577, 2015.

[8] A. Iqbal, A. Smida, N. Mallat et al., "Frequency and pattern reconfigurable antenna for emerging wireless communication systems," Electronics, vol. 8, no. 4, p. 407, 2019.

[9] I. A. Shah, S. Hayat, A. Basir et al., "Design and analysis of a hexa-band frequency reconfigurable antenna for wireless communication," AEU - International Journal of Electronics and Communications, vol. 98, pp. 80-88, 2019.

[10] A. Iqbal, A. Smida, L. F. Abdulrazak et al., "Low-profile frequency reconfigurable antenna for heterogeneous wireless systems," Electronics, vol. 8, no. 9, p. 976, 2019.

[11] G. Jin, C. Deng, J. Yang, Y. Xu, and S. Liao, "A new differentially-fed frequency reconfigurable antenna for WLAN and sub-6GHz 5G applications," IEEE Access, vol. 7, pp. 56539-56546, 2019.

[12] G. Jin, C. Deng, Y. Xu, J. Yang, and S. Liao, "Differential frequency-reconfigurable antenna based on dipoles for sub-6 GHz 5G and WLAN applications," IEEE Antennas and Wireless Propagation Letters, vol. 19, no. 3, pp. 472-476, 2020.

[13] Y. Li, Z. Zhao, Z. Tang, and Y. Yin, "Differentially fed, dual-band dual-polarized filtering antenna with high selectivity for $5 \mathrm{G}$ sub$6 \mathrm{GHz}$ base station applications," IEEE Transactions on Antennas and Propagation, vol. 68, no. 4, pp. 3231-3236, 2020.

[14] S. Ullah, I. Ahmad, Y. Raheem, S. Ullah, T. Ahmad, and U. Habib, "Hexagonal shaped CPW feed based frequency reconfigurable antenna for WLAN and sub-6 GHz $5 \mathrm{G}$ applications," in 2020 International Conference on Emerging Trends in Smart Technologies (ICETST), pp. 1-4, Karachi, Pakistan, 2020.

[15] S. Raman, N. Timmons, and J. Morrison, "Gain enhanced pattern reconfigurable planar Yagi-Uda antenna on coplanar structure," Electronics Letters, vol. 49, no. 25, pp. 1593-1595, 2013.

[16] B. Barakali, K. L. Ford, and S. Khamas, "A pattern reconfigurable microstrip dipole antenna with PRS gain enhancement," in 2017 11th European Conference on Antennas and Propagation (EUCAP), pp. 3131-3134, Paris, France, 2017.

[17] A. Sowmyadevi, P. Mathur, A. R. Chandran, N. Timmons, J. Morrison, and S. Raman, " $2.45 \mathrm{GHz}$ pattern reconfigurable antenna for wireless sensor network applications," in 2019 URSI Asia-Pacific Radio Science Conference (AP-RASC), pp. 1-4, New Delhi, India, 2019.

[18] H. Tian, L. J. Jiang, and T. Itoh, "A compact single-element pattern reconfigurable antenna with wide-angle scanning tuned by a single varactor," Progress In Electromagnetics Research, vol. 92, pp. 137-150, 2019.

[19] Z.-L. Lu, X.-X. Yang, and G.-N. Tan, "A multidirectional pattern-reconfigurable patch antenna with CSRR on the ground," IEEE Antennas and Wireless Propagation Letters, vol. 16, pp. 416-419, 2017.

[20] L. Zhong, J.-S. Hong, and H.-C. Zhou, "A novel patternreconfigurable cylindrical dielectric resonator antenna with enhanced gain," IEEE Antennas and Wireless Propagation Letters, vol. 15, pp. 1253-1256, 2016.

[21] W. D. Ma, G. M. Wang, Y. W. Wang, and B. F. Zong, "Compact microstrip antenna with pattern-reconfigurable characteristic," Radioengineering, vol. 26, no. 3, pp. 662-667, 2017.

[22] H. A. Majid, M. K. A. Rahim, M. R. Hamid, and M. F. Ismail, "Frequency and pattern reconfigurable slot antenna," IEEE Transactions on Antennas and Propagation, vol. 62, no. 10, pp. 5339-5343, 2014.

[23] S. N. M. Zainarry, N. Nguyen-Trong, and C. Fumeaux, "A frequency- and pattern-reconfigurable two-element array antenna," IEEE Antennas and Wireless Propagation Letters, vol. 17, no. 4, pp. 617-620, 2018.

[24] N. Ramli, M. T. Ali, M. T. Islam, A. L. Yusof, and S. Muhamud-Kayat, "Aperture-coupled frequency and patterns reconfigurable microstrip stacked array antenna," IEEE Transactions on Antennas and Propagation, vol. 63, no. 3, pp. 1067-1074, 2015.

[25] R. Dewan, M. K. A. Rahim, M. R. Hamid, M. Himdi, H. B. A. Majid, and N. A. Samsuri, "HIS-EBG unit cells for pattern and frequency reconfigurable dual band array antenna," Progress In Electromagnetics Research, vol. 76, pp. 123-132, 2018.

[26] Y. P. Selvam, M. Kanagasabai, M. G. N. Alsath et al., "A lowprofile frequency- and pattern-reconfigurable antenna," IEEE Antennas and Wireless Propagation Letters, vol. 16, pp. 3047-3050, 2017.

[27] Z. Zhu, P. Wang, S. You, and P. Gao, "A flexible frequency and pattern reconfigurable antenna for wireless systems," Progress In Electromagnetics Research, vol. 76, pp. 63-70, 2018.

[28] L. Han, C. Wang, W. Zhang, R. Ma, and Q. Zeng, "Design of frequency- and pattern-reconfigurable wideband slot antenna," International Journal of Antennas and Propagation, vol. 2018, 7 pages, 2018.

[29] F. Hafeez, U. U. Sheikh, N. Alkhaldi, H. Z. Al Garni, Z. A. Arfeen, and S. A. Khalid, "Insights and strategies for an autonomous vehicle with a sensor fusion innovation: a fictional outlook," IEEE Access, vol. 8, pp. 135162-135175, 2020.

[30] A. F. Molisch, M. Z. Win, Y.-S. Choi, and J. H. Winters, "Capacity of MIMO systems with antenna selection," IEEE Transactions on Wireless Communications, vol. 4, no. 4, pp. 1759-1772, 2005.

[31] M. Albreem, M. Juntti, and S. Shahabuddin, "Efficient initialisation of iterative linear massive MIMO detectors using a stair matrix," Electronics Letters, vol. 56, no. 1, pp. 50-52, 2020. 